\title{
Characteristics of Mixed Polyvinyl Alcohol and Chitosan Obtained from Shrimp Shells and Squid Pens for Electromagnetic Wave Absorber
}

\author{
Nofrijon Sofyan ${ }^{\# 1}$, Farid Nur Sany ${ }^{\# 2}$, Akhmad Herman Yuwono ${ }^{\# 3}$, Donanta Dhaneswara ${ }^{\# 4}$ \\ \#Department of Metallurgical and Materials Engineering, Faculty of Engineering, \\ Universitas Indonesia, Depok 16424, Indonesia \\ ${ }^{1}$ nofrijon.sofyan@ui.ac.id \\ 2 farid.nursany@gmail.com \\ 3ahyuwono@eng.ui.ac.id \\ 4donanta.dhaneswara@ui.ac.id
}

\begin{abstract}
One of the potential materials developed for electromagnetic interference shielding and or anti radio detecting and ranging (radar) purposes is chitosan, however, its capability to absorb the electromagnetic waves needs to be characterized. This work aims at studying the characteristics of polyvinyl alcohol (PVA mixed with) $\alpha$-chitosan obtained from shrimp shells and $\beta$-chitosan obtained from squid pens for electromagnetic wave absorber. Samples were prepared with weight ratio variation of chitosan from each source at $0.5,1,1.5$ and $2 \mathrm{wt.} \%$ and homogenously mixed with 8 wt.\% of PVA. The solution mixture was casted into a petri dish through solution casting methods. The samples were characterized by using thickness measurer for the thickness, scanning electron microscope (SEM) for microstructure and surface morphology, X-ray powder diffractometer (XRD) for phase identification, Fourier transform infra-red spectroscopy (FTIR) for functional groups, and network analyser to measure the reflection loss characteristics. The electromagnetic wave absorption characteristics show that $\alpha$ chitosan has an absorption intensity with minimum value of $-14.92 \mathrm{~dB}$ at $2.0 \mathrm{wt} \%$ o-chitosan and maximum value of $-\mathbf{3 1 . 0 3} \mathrm{dB}$ at $0.5 \mathrm{wt} . \% \alpha$-chitosan. Similarly, $\beta$-chitosan showed an absorption intensity with minimum value of $-15.48 \mathrm{~dB}$ at $2.0 \mathrm{wt}$.\% $\beta$-chitosan and maximum value of $-31.94 \mathrm{~dB}$ at $0.5 \mathrm{wt} . \% \beta$ chitosan. These trends show that the materials have a potential to be further developed for anti-radar capability.
\end{abstract}

Keyword - Chitosan, Electromagnetic interference, Polyvinyl alcohol, Radar, Reflection loss

\section{INTRODUCTION}

As an archipelago with a vast ocean, Indonesia has huge potential in terms of seafood products such as shrimp, crab, lobster, krill and squid. However, the seafood processing will also produce large quantities of byproducts in the forms of waste. Handling of this waste may lead to environmental hazard and human health problems if a proper waste management and treatment is not performed. On the other hand, this waste could be turned into high value, useful products. Utilization of shrimp shell and squid pen wastes as a source of chitin, which can be further processed to obtain chitosan, is one of the solutions to minimize the waste, to produce valuable compound, and at the same time to overcome the aforementioned problems.

Chitosan is a linear polysaccharide composed of randomly distributed $\beta$ - $(1 \rightarrow 4)$-linked D-glucosamine (deacetylated unit) and N-acetyl-D-glucosamine (acetylated unit), which can be produced by deacetylation of chitin [1]. Chitin is the structural element found in many crustaceans, and depending on its source, chitin could be found as two allomorphs, i.e. in the forms $\alpha$ and $\beta$ types [2]. $\alpha$-Chitin is the most abundant and can be found in various marine living organisms such as shrimp shells, krill, and lobster, whereas $\beta$-chitin is found in association mostly with squid pens [3], [4].

Investigators have found that chitosan has many chemical and biological activities with application in many fields. Chitosan is extensively used in the biomedical fields such as for cartilage regeneration [5] and drug delivery [6], [7], in the pharmaceuticals [8], and in the industrial fields such as for water treatment [9], [10]. Furthermore, chitosan is a polycationic compound with a lot of positive charge from the nitrogen group [11]. Because of its polycationic nature, chitosan tends to have a characteristic of a dielectric material [12]. At the same time, a material with high dielectric properties will be able to store the absorbed wave in large quantities [13]. When this material is included as part of composite materials, significant improvements can be achieved in the electromagnetic interference (EMI) devices [14] and or antiradar purposes [15]. 
Many studies have been done focusing on blending of polyvinyl alcohol (PVA) film layer and chitosan obtained from $\alpha$-chitin derivative only [4]. This is because the $\alpha$-chitin is easily obtained. In fact, in addition to $\alpha$-chitin there is also $\beta$-chitin, which is relatively more difficult to obtain due to its rare source [2] and only few studies focusing on this material. In this work, two sources of chitosan are considered, i.e. shrimp shells that produce $\alpha$-chitin and squid pens that produce $\beta$-chitin [4], [16]. The work aims at studying the characteristics of polyvinyl alcohol (PVA) mixed with $\alpha$-chitosan obtained from shrimp shells and $\beta$-chitosan obtained from squid pens for electromagnetic wave absorber. The composition of PVA and chitosan was varied to obtain a composite film that can optimally absorb electromagnetic waves emitted from an electromagnetic source and the results are given and discussed.

\section{EXPERIMENTAL SETUP}

\section{A. Materials}

Two sources of chitosan were considered in this study, i.e. the shrimp shells that produce $\alpha$-chitin and squid pens that produce $\beta$-chitin. Chitosan from the derivative of these two sources were purchased from Marine Bio Resources Co., Ltd., Thailand, with deacetylation degree $\geqslant 90 \%$. Polyvinyl alcohol (PVA, MW $\sim 60000$ ) was obtained from Merck, Germany, whereas glycerol was obtained from Sigma Aldrich.

\section{B. Composite Preparation}

The composite film was prepared in according to the work of others [17] in which PVA and chitosan were mixed in a proportion through a solution casting in a petri dish. The film was prepared by dissolving 24 grams of PVA in 276 grams of distilled water to form PVA solution at a temperature of $90{ }^{\circ} \mathrm{C}$ and was kept at room temperature for 24 hours. Furthermore, 0.5, 1.0, 1.5 and 2.0 grams of $\alpha$-chitosan were dissolved in 99.5, 99, 98.5 and 98 grams of acetic acid $2 \%$, respectively, at room temperature to form $0.5,1.0,1.5$ and $2.0 \mathrm{wt} . \% \alpha$-chitosan solutions. After the solutions were prepared, 10 grams of PVA solution were mixed and homogenized with 40 grams of each $\alpha$-chitosan solution to form $8 \mathrm{wt} . \%$ PVA and 0.92 grams of glycerol to form a solution composite film-forming. The homogenized mixture was then casted onto $9.5 \mathrm{~cm}$ diameter petri dish and allowed to stand in an oven for 48 hours at $40{ }^{\circ} \mathrm{C}$ and ambient relative humidity. The dried film was then peeled off the petri dish and kept in a desiccator for subsequent characterization and experiments. The aforementioned steps are repeated to fabricate the film from $\beta$-chitosan solution.

\section{Characterization}

The film thickness was measured by using a coating thickness gauge (Checkline DCF-900) from five different points on the film surface; structural characterization was performed by using X-ray diffractometer (XRD, PANalytical - Empyrean), functional groups by using a Fourier Transform Infrared (FTIR) spectroscopy (PerkinElmer Spectrum Two), surface morphology of the film by using scanning electron microscope (SEM, JEOL JSM-6510LA), and reflection loss by using a network analyser (Agilent Technologies N5230C) with the frequency varied within the range of $3 \mathrm{GHz}$ to $5 \mathrm{GHz}$.

\section{III.RESULT AND DISCUSSION}

The thickness of the composite films was measured and compared after curing process. At 0.5, 1.0, 1.5 and $2.0 \mathrm{wt} . \% \alpha$-chitosan, the average composite film thickness is $338,357,391$, and 401 microns, respectively, whereas at $0.5,1.0,1.5$ and $2.0 \mathrm{wt} . \% \beta$-chitosan, the average composite film thickness is $320,334,338$, and 377 microns, respectively. The results showed that the composite film thickness increases with the increase of chitosan concentration and that the composite film with $\alpha$-chitosan is thicker than that of with $\beta$-chitosan. This can be understood since the bulk density of $\alpha$-chitosan from shrimp shells $(\sim 0.3 \mathrm{~g} / \mathrm{cm} 3)$ is higher than that of $\beta$ chitosan from squid pen $(\sim 0.15 \mathrm{~g} / \mathrm{cm} 3)$ [18].

Crystal structure of the composites was examined through X-ray diffraction testing. As a comparison, the same testing was also performed for the as-received $\alpha$-chitosan, $\beta$-chitosan, and PVA. For the chitosan, the results show the emergence of two diffraction peaks both in the as-received $\alpha$-chitosan and $\beta$-chitosan as can be seen in Figure 1. The diffraction peaks of the $\alpha$-chitosan appear in the range of 2-theta 10.1 and 19.8 whereas the diffraction peaks of the $\beta$-chitosan appear in the range of 2-theta 10.5 with less intensity and 2-theta 19.9. These diffraction patterns are in agreement with other results found by other investigators. Based on other research, there are two diffraction peaks of $\alpha$-chitosan that appears on the range of 2-theta 10 and 20 [19]. Another study revealed that there are two peaks of $\alpha$-chitosan in the range of diffraction angle of 2-theta 9.1 9.2 and $19.1-19.2$ [20]. For as $\beta$-chitosan, a research has shown that there are two diffraction peaks appeared in the range of 2-theta 10 and 19 [21], whereas other research concluded that the diffraction peaks of both $\alpha$ chitosan and $\beta$-chitosan occurred in the range of 2-theta $9-10$ and $19-20$ [4].

As can also be seen in Fig. 1, the X-ray diffraction pattern of the as-received PVA revealed a small peak at 2theta 10.8 and a strong crystalline diffraction at around 2-theta 19.1 with a shoulder at around 2-theta 22.7. These two latter diffraction peaks are characteristic of PVA from (101) and (200) planes with a monoclinic unit cell [22]. Another small peak is found at around 2-theta 40.1. 

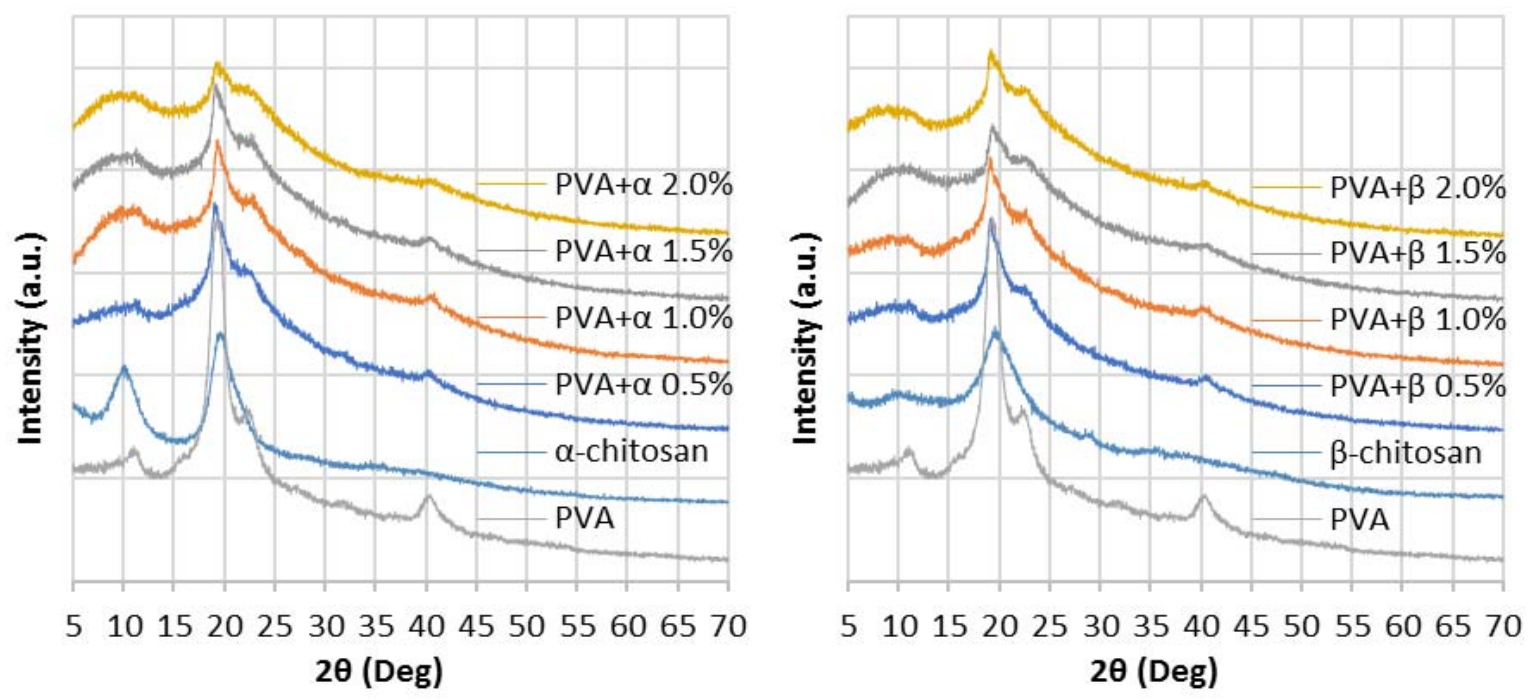

Fig. 1. X-ray diffraction patterns of (a) PVA at variation concentrations of $\alpha$-chitosan and (b) PVA at variation concentrations of $\beta$-chitosan

Fourier transform infrared (FTIR) characteristic of PVA at various $\alpha$-chitosan and $\beta$-chitosan concentrations at wavenumber from $500-4000 \mathrm{~cm}-1$ are given in Fig. 2. As a comparison, the characteristic of pure PVA, pure $\alpha$ - and $\beta$-chitosan are also given. As seen in the figure, the spectrum shows the appearance of hydrogen bonded $\mathrm{OH}$ and $\mathrm{NH}_{2}$ stretching bands ranging from 3070 to $3450 \mathrm{~cm}-1$ and bands at around 2871 to 2920 represent $\mathrm{C}-\mathrm{H}$ groups stretching [23]. The amino groups show a band around $1584 \mathrm{~cm}-1$, bands at 1375 and 1420 are attributed to the presence of methylene and methyl groups of chitosan respectively, whereas the asymmetrical vibration of CO shows a band at $1150 \mathrm{~cm}-1$ [21]. For the as-received materials, the intensities are much lower compared to those of the composite films. The increase of the band intensities in the composite films is expected to be due to the introduction of additional group into the composite blends, which is in agreement with the results found by others [23], [24].

Scanning electron microscope was used to study the morphological features of the composite films. Figure 3 shows secondary electron images of PVA mixed with $0.5,1.0,1.5$, and 2.0 wt. $\% \alpha$-chitosan, whereas Fig. 4 shows secondary electron images of PVA mixed with $0.5,1.0,1.5$, and $2.0 \mathrm{wt} . \% \beta$-chitosan.
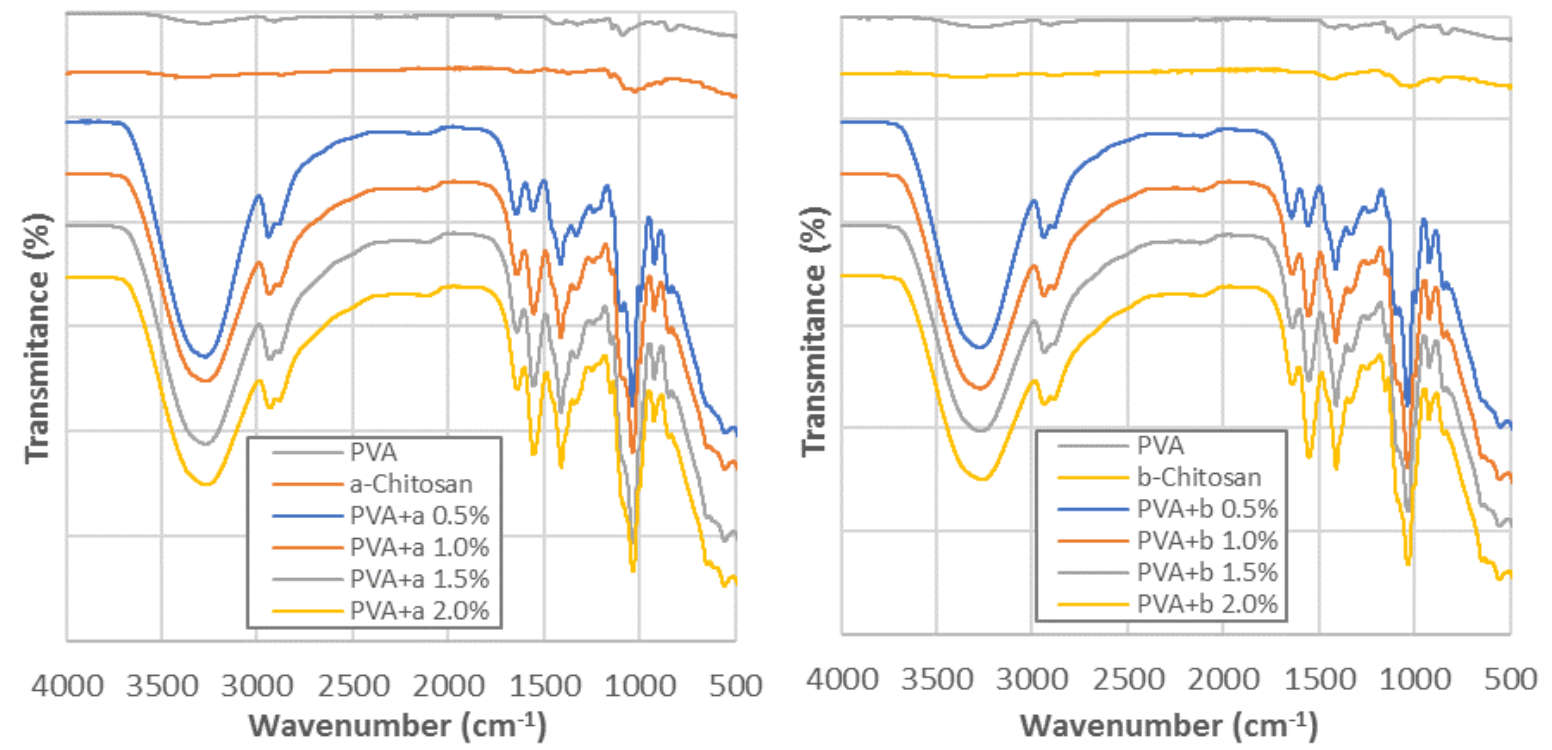

Fig. 2. FTIR transmittance characteristic of (a) PVA at various concentration of $\alpha$-chitosan and (b) PVA at various concentration of $\beta$ chitosan from $500-4000 \mathrm{~cm}^{-1}$ 


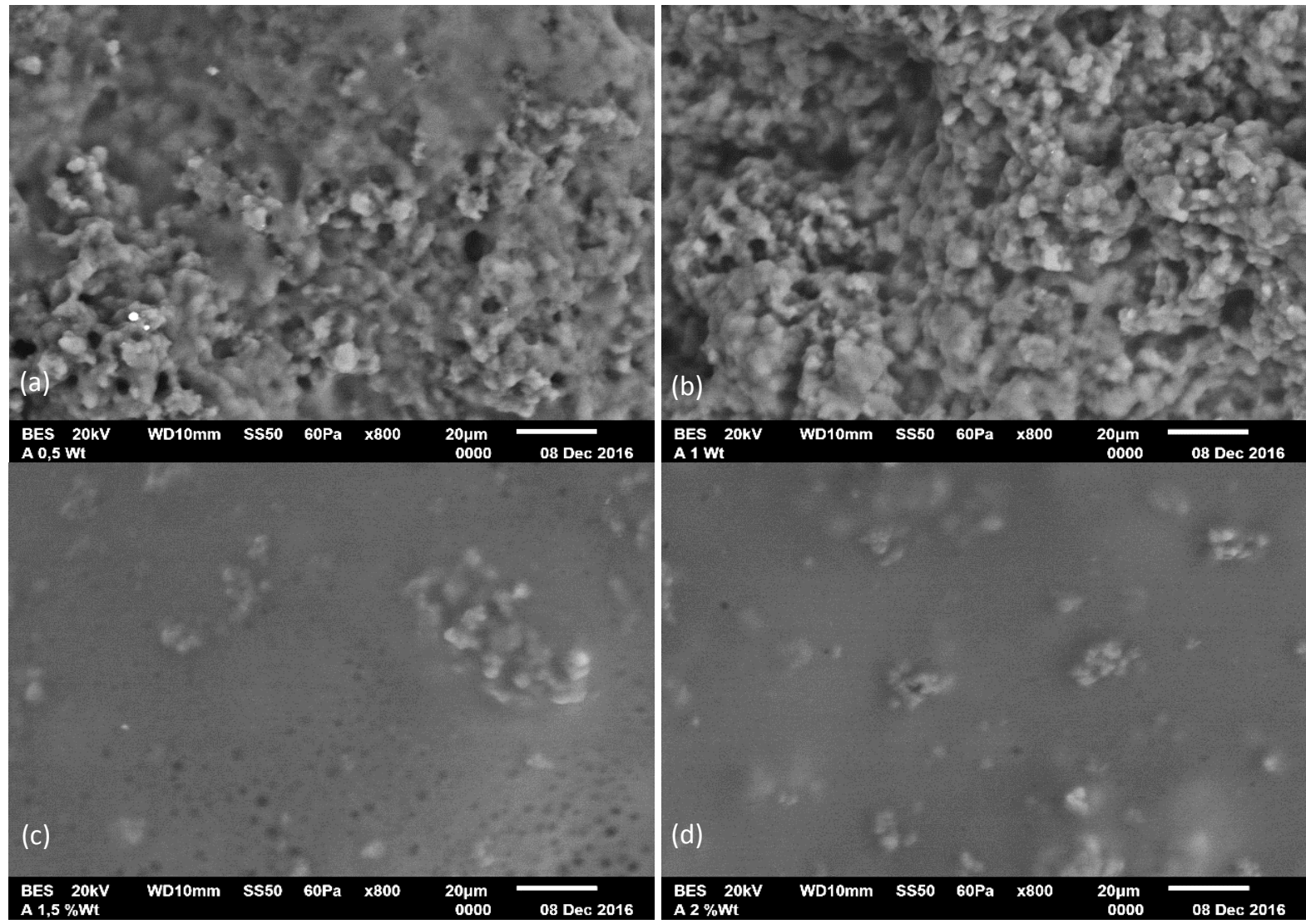

Fig. 3. Secondary electron images of (a) PVA at 0.5 wt. $\% \alpha$-chitosan, (b) PVA at 1.0 wt. $\% \alpha$-chitosan, (c) PVA at 1.5 wt. $\% \alpha$-chitosan, (d) PVA at $2.0 \mathrm{wt} . \% \alpha$-chitosan.

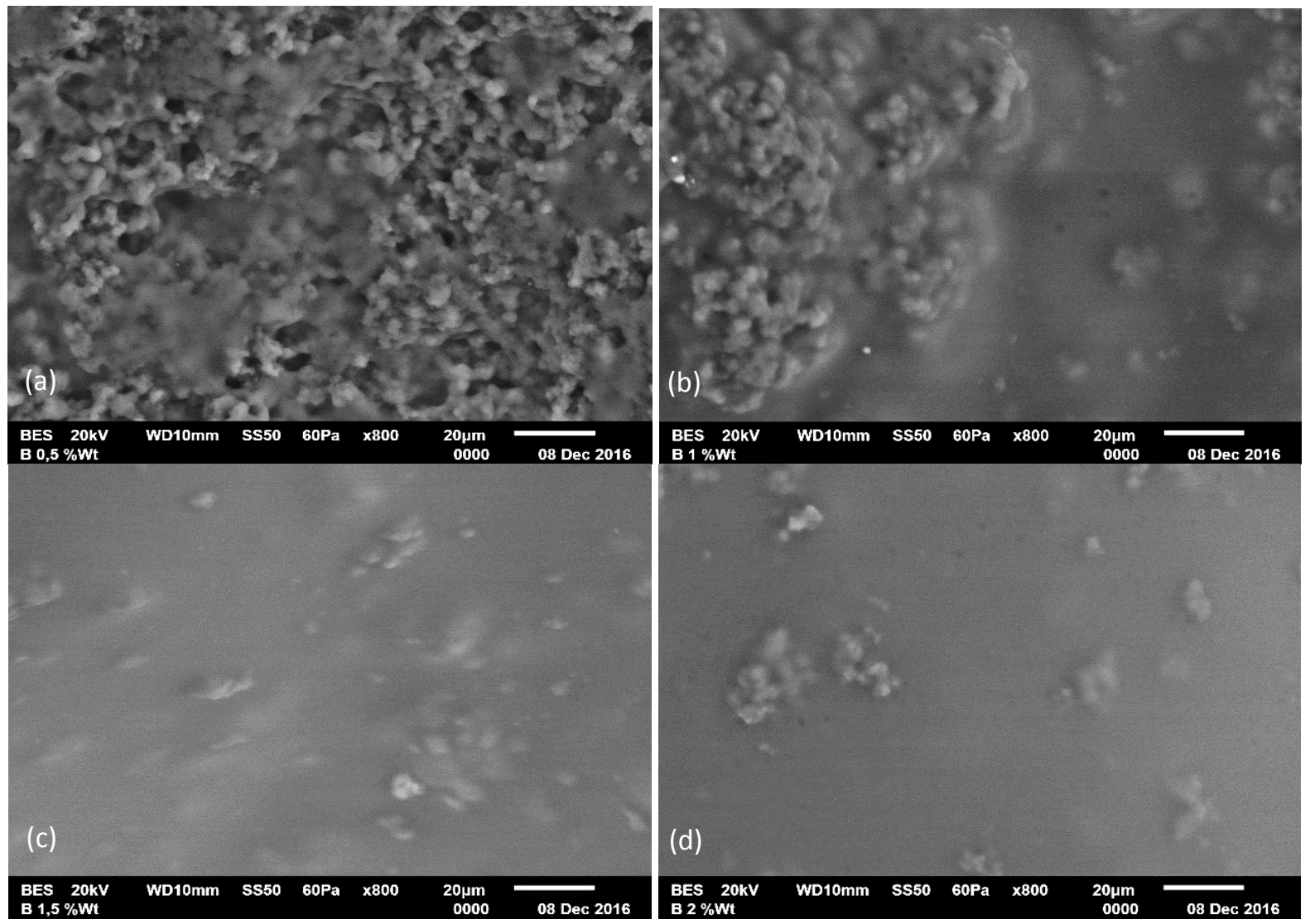

Figure 4. Secondary electron images of (a) PVA at 0.5 wt.\% $\beta$-chitosan, (b) PVA at 1.0 wt. $\% \beta$-chitosan, (c) PVA at 1.5 wt.\% $\beta$-chitosan, (d) PVA at $2.0 \mathrm{wt} . \% \beta$-chitosan. 
Visually, the composite films appeared to be smooth and transparent, however, as seen detail in Fig. 3 and Fig. 4, secondary electron images reveal a microstructure with particles from both PVA and chitosan distributed homogeneously. In both of the composites, they reveal the same tendency in which increasing the chitosan content results in smoother of the surface microstructure. It seems that the more the chitosan, the more the probability that chitosan will fill the gap amongst the PVA particles, and thus the microstructure of the samples becomes more compact and thicker [21] as has been indicated previously in the film thickness. Furthermore, with the increase of chitosan contents, there would be formation of homogeneous interaction between chitosan and PVA, which is mostly resulted from the interactions of hydrogen bonds between the functional groups of the mixed component, i.e. $-\mathrm{OH}$ and $-\mathrm{NH}_{2}$ groups in chitosan and $-\mathrm{OH}$ groups in PVA [25].

Reflection loss analysis was conducted to examine the electromagnetic wave absorption characteristics of the composite films. However, due to technical issues of the equipment use in this work, the frequency used was only varied within the range of $3 \mathrm{GHz}$ to $5 \mathrm{GHz}$. The result is given in Fig. 5. As seen in the figure, Fig 5(a) is the reflection loss characteristics of PVA at various concentration of $\alpha$-chitosan, whereas Fig. 5(b) is the reflection loss characteristics of PVA at various concentration of $\beta$-chitosan.
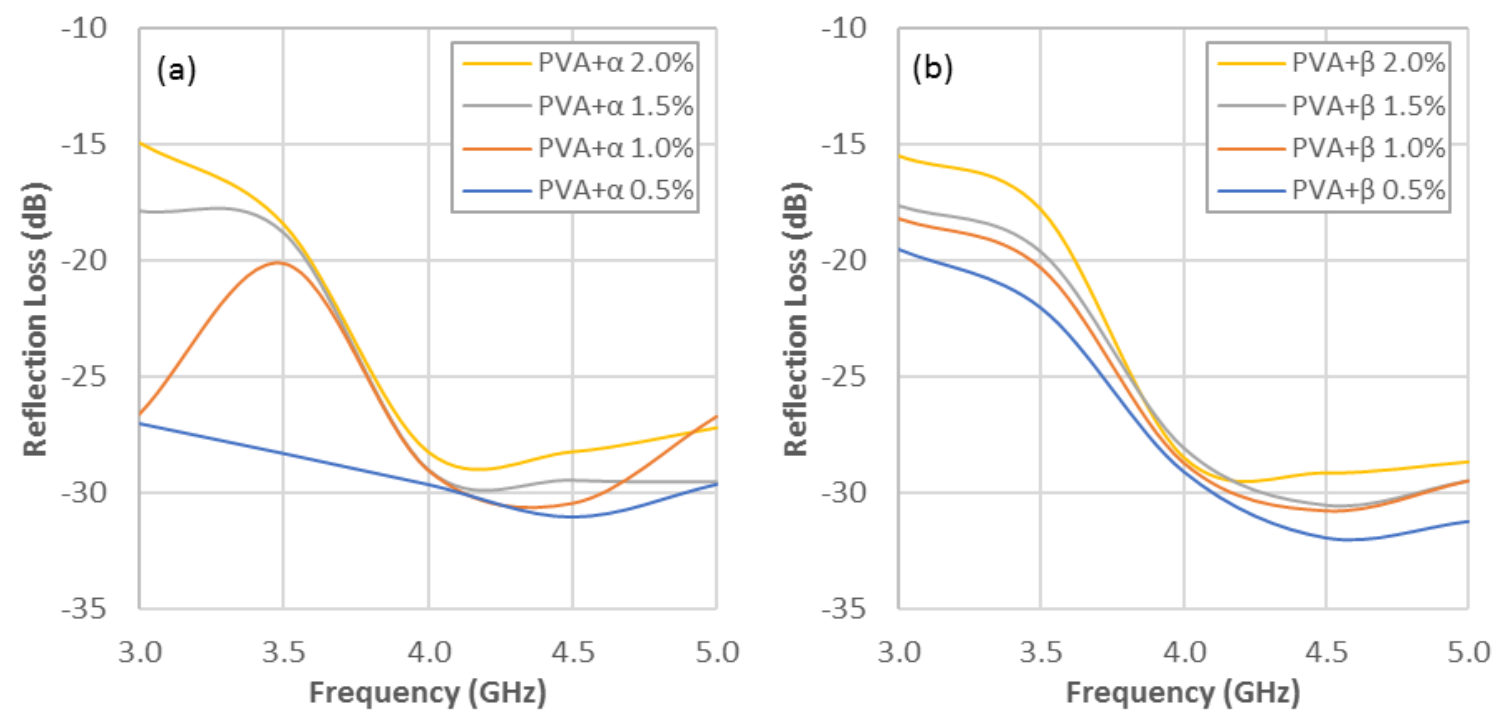

Fig. 5. Reflection loss characteristics of (a) PVA at various concentration of $\alpha$-chitosan and (b) PVA at various concentration of $\beta$-chitosan from $3.0-5.0 \mathrm{GHz}$

The results from electromagnetic wave absorption characteristics show that $\alpha$-chitosan has an absorption intensity with minimum value of $-14.92 \mathrm{~dB}$ at $2.0 \mathrm{wt} \% \alpha$-chitosan and maximum value of $-31.03 \mathrm{~dB}$ at 0.5 wt. $\% \alpha$-chitosan. Similarly, $\beta$-chitosan showed an absorption intensity with minimum value of $-15.48 \mathrm{~dB}$ at 2.0 wt. $\% \beta$-chitosan and maximum value of $-31.94 \mathrm{~dB}$ at $0.5 \mathrm{wt} . \% \beta$-chitosan.

In both of the composites, there is a tendency that increasing the concentrations of the chitosan noticeable decreases the absorption of the electromagnetic wave. This decreasing characteristic could be attributed to the dielectric behaviour of the materials in which increasing the chitosan concentration would lower the dielectric permittivity associated with the energy storage capability [26]. However, as seen in the graphs, increasing the electromagnetic frequency tends to increase the reflection loss at certain degree.

\section{IV.CONCLUSION}

Characteristics of mixed polyvinyl alcohol and chitosan obtained from shrimp shells and squid pens for electromagnetic wave absorber have been examined. The average thickness of PVA- $\alpha$-chitosan composite is 338 , 357,391 and 401 microns at $0.5,1.0,1.5$, and $2.0 \mathrm{wt} . \% \alpha$-chitosan, respectively, whereas the average thickness of PVA- $\beta$-chitosan composite is $321,334,338$ and 377 microns at $0.5,1.0,1.5$, and 2.0 wt.\% $\beta$-chitosan, respectively. The electromagnetic wave absorption characteristics show that $\alpha$-chitosan has an absorption intensity with a minimum value of $-14.92 \mathrm{~dB}$ at $2.0 \mathrm{wt} \% \alpha$-chitosan and a maximum value of $-31.03 \mathrm{~dB}$ at 0.5 wt.\% $\alpha$-chitosan. Similarly, $\beta$-chitosan showed an absorption intensity with a minimum value of $-15.48 \mathrm{~dB}$ at $2.0 \mathrm{wt} . \% \beta$-chitosan and a maximum value of $-31.94 \mathrm{~dB}$ at $0.5 \mathrm{wt} . \% \beta$-chitosan. These trends show an indication that the composite materials have a potential to be further developed for electromagnetic interference shielding and or antiradar purposes.

\section{REFERENCES}

[1] C. Choi, J-P. Nam and J-W. Nah, “Application of Chitosan and Chitosan Derivatives as Biomaterials,” J. Ind. Eng. Chem., Vol. 33, 2016, pp. $1-10$

[2] K. M. Rudall and W. Kenchington, “The Chitin System,” Biol. Rev. Camb. Philos. Soc,, Vol. 40, 1973, pp. 597-636. 
[3] K. M. Rudall, "Chitin and Its Association with Other Molecules,” J. Polym. Sci., Polym. Symp., Vol. 28, 1969 , pp. 83-102.

[4] M. Rinaudo, "Chitin and Chitosan: Properties and Applications," Prog. Polym. Sci., Vol. 31, 2006, pp. 603 - 632.

[5] M. Dash, F. Chiellini, R. M. Ottenbrite and E. Chiellini, "Chitosan-A Versatile Semi Synthetic Polymer in Biomedical Applications," Prog. Polym. Sci., Vol. 36, 2011,pp. $981-1014$.

[6] R. Riva, H. Ragelle, A. des Rieux, N. Duhem, C. Jerome and V. Preat, "Chitosan and Chitosan Derivatives in Drug Delivery and Tissue Engineering," Adv. Polym. Sci., Vol. 244, 2011, pp. $19-44$.

[7] E. Kusrini, R. Arbianti, N. Sofyan, M. A. A. Abdullah and F. Andriani, "Modification of Chitosan by Using Samarium for Potential Use in Drug Delivery System," Spectrochim. Acta Mol. Biomol. Spectrosc., Vol. 120, 2014, pp. 77-83.

[8] J. Varshosaz, F. Jaffari and S. Karimzadeh, "Development of Bioadhesive Chitosan Gels for Topical Delivery of Lidocaine," Sci. Pharm., Vol. 74, 2006, pp. 209-223.

[9] C. Dong, W. Chen and C. Liu, "Flocculation of Algal Cells by Amphoteric Chitosan-Based Flocculant," Bioresour. Technol., Vol. 170, 2014, pp. $239-247$.

[10] E. Kusrini, N. Sofyan, N. Suwartha, G. Yesya and C. R. Priadi, "Chitosan-Praseodymium Complex for Adsorption of Fluoride Ions from Water, J. Rare Earths," Vol. 33, 2015, pp. $1104-1113$.

[11] W. Wang, S. Bo, S. Li and W. Qin, "Determination of the Mark-Houwink Equation for Chitosans with Different Degrees of Deacetylation,” Int. J. Biol. Macromolec., Vol. 13, 1991, pp. 281-285.

[12] A. A. Begum, R. Radhakrishnan and K. P. Nazeer, "Study of Structure-Property Relationship on Sulfuric Acid Crosslinked Chitosan Membranes," Malaysian Polymer Journal, Vol. 6, 2011, pp. 27-38.

[13] R. M. McMeeking and C. M. Landis, "Electrostatic Forces and Stored Energy for Deformable Dielectric Materials," J. Appl. Mech., Vol. 72, 2005, pp. $581-590$.

[14] M. M. Abdi, A. B. Kassim, H. N. M. E. Mahmud, W. M. M. Yunus and Z. A. Talib, "Electrical and Shielding Properties of Conductive Polymer Composite Matrix with Chitosan,” Solid State Sci. Technol., Vol. 17, 2009, pp. 12 - 21.

[15] P. Chandrasekhar and K. Naisdham, "Broadband Microwave Absorption and Shielding Properties of a Poly(Aniline)," Synth. Met., Vol. 105, 1999, pp. $115-120$.

[16] I. Hamed, F. Ozogul and J. M. Regenstein, "Industrial Applications of Crustacean By-Products (Chitin, Chitosan, and Chitooligosaccharides): A Review,” Trends Food Sci. Technol., Vol. 48, 2015, pp. 40 - 50.

[17] S. Liang, L. Liu, Q. Huang and K. L. Yam, "Preparation of Single or Double-Network Chitosan/Poly (vinyl alcohol) Gel Films through Selectively Cross-Linking Method," Carbohydr. Polym., Vol. 77, 2009, pp. 718 - 724.

[18] A. Shavandi, A. A. Bekhit, A. E.-D. A. Bekhit, Z. Sun and M. A. Ali, "Preparation and Characterisation of Irradiated Crab Chitosan and New Zealand Arrow Squid Pen Chitosan," Mater. Chem. Phys., Vol. 167, 2015, pp. 295 - 302.

[19] F. C. Vasconcellos, G. A. S. Goulart and M. M. Beppu, "Production and characterization of chitosan microparticles containing papain for controlled release applications," Powder Technol., Vol. 205, 2011, pp. 65-70

[20] M.-T. Yen, J.-H. Yang and J.-L. Mau, "Physicochemical Characterization of Chitin and Chitosan from Crab Shells," Carbohydr. Polym., Vol. 75, 2009, pp. $15-21$.

[21] A. Shavandi, A. E.-D. A. Bekhit, Z. Sun, A. Ali and M. Gould, "A Novel Squid Pen Chitosan/Hydroxyapatite/ $\beta$-Tricalcium Phosphate Composite for Bone Tissue Engineering,” Mater. Sci. Eng. C, Vol. 55, 2015, pp. 373-383.

[22] R. Ricciardi, F. Auriemma, C. De Rosa and F. Lauprêtre, "X-ray Diffraction Analysis of Poly(vinyl alcohol) Hydrogels, Obtained by Freezing and Thawing Techniques," Macromolecules, Vol. 37, 2004, pp. 1921-1927.

[23] S. Liang, Q. Huang, L. Liu and K. L. Yam, "Microstructure and Molecular Interaction in Glycerol Plasticized Chitosan/Poly(vinyl alcohol) Blending Films,” Macromol. Chem. Phys., Vol. 210, 2009, pp. 832-839.

[24] I. Bano, M. A. Ghauria, T. Yasin, Q. Huang, A. D’S. Palaparthi, "Characterization and Potential Applications of Gamma Irradiated Chitosan and Its Blends with Poly(vinyl alcohol)," Int. J. Biol. Macromol., Vol. 65, 2014, pp. 81-88.

[25] E. A. El-Hefian, M.M. Nasef, and A. H. Yahaya, "The Preparation and Characterization of Chitosan/Poly(vinyl alcohol) Blended Films," E-J. Chem., Vol. 7, 2010, pp. 1212-1219.

[26] C. G. A. Lima, R. S. de Oliveira, S. D. Figueiro, C. F. Wehmann, J. C. Goes, and A. S. B. Sombra, "DC Conductivity and Dielectric Permittivity of Collagen-Chitosan Films,”J. Mater. Chem. Phys., Vol. 99, 2006, pp. 284-288.

\section{AUTHOR PROFILE}

Nofrijon Sofyan is an Associate Professor at the Department of Metallurgical and Materials Engineering, Universitas Indonesia. He obtained his B.Sc. in Chemistry from Andalas University, Padang, 1992, and M.Sc. in Materials Science from Universitas Indonesia, Jakarta, 1997. He received his Ph.D. in Materials Engineering from Auburn University, USA, 2008. His research areas include nanomaterials, dye-sensitized solar cells, lithium ion batteries, and superconductors.

Farid Nur Sany is an Engineer at PT. JGC Indonesia. He obtained his B.Sc. in Mechanical Engineering from Surabaya Institute of Technology, Indonesia, 2011. He received his M.Sc. in Metallurgical and Materials Engineering, Universitas Indonesia, 2017.

Akhmad Herman Yuwono is a Professor at the Department of Metallurgical and Materials Engineering, Universitas Indonesia. He obtained his B.Eng. in Metallurgical Engineering from Universitas Indonesia, 1994, and M.Phil.Eng in Materials Engineering from University of Cambridge, United Kingdom, 1998. He received his Ph.D. in Materials Science and Engineering from National University of Singapore, 2008. His research areas include nanomaterials and dye-sensitized solar cells.

Donanta Dhaneswara is an Associate Professor at the Department of Metallurgical and Materials Engineering, Universitas Indonesia. He obtained his B.Eng. in Metallurgical Engineering from Universitas Indonesia, 1989, and M.Sc. in Materials Science from Universitas Indonesia, 1994. He received his Ph.D. in Materials Science from Universitas Indonesia, 2006. His research area focuses on mesoporous materials and thin-walled ductile iron. 